\title{
Renal Hücreli Kanser Nedeni İle Yapılan Laparoskopik ve Robot Yardımlı Nefron Koruyucu Cerrahi Sonrası Sınır Pozitifliğinin İnsidansı ve Kliniğe Etkisi
}

\author{
Hasan Anıl Atalay ${ }^{1}$, Lutfi Canat ${ }^{1}$, Volkan Ülker ${ }^{1}$, IIter Alkan ${ }^{1}$, Fatih Altunrende ${ }^{1}$
}

${ }^{1}$ Okmeydanı Eğitim ve Araştırma Hastanesi, Üroloji Kliniği, Istanbul

Giriş

$\mathrm{M}$ odern görüntüleme yöntemlerinin yaygınlaşması ile böbrek kanseri tanısı daha sık konulmakta ve tedavi seçenekleri arasındaki nefron koruyucu cerrahi (NKC) daha sık uygulanmaktadır. Açık parsiyel nefrektomi (APN) ile radikal nefrektominin (RN) karşılaştırıldı $\breve{g}_{1}$ birçok çalışmada kansere özgü sağ kalım bakımından fark saptanmamıştır (1). Günümüzde laparoskopik parsiyel nefrektomi (LPN) ve robot yardımlı parsiyel nefrektomi (RYPN) onkolojik ve cerrahi sonuçlar açısından, APN'ye onkolojik açıdan eşdeğer bir alternatif olarak ortaya çıkmıştır $(2,3)$.

Renal hücreli kanser (RHK) nedeni ile yapılan NKC'de klasik olarak önerilen cerrahi yöntem, tümörden yeterli uzaklıktaki sağlıklı alandan eksizyonun yapılmasıdır (4). Fakat bazı vakalarda tümörün santral oluşu veya hiler bölgeye yakınlığı, cerrahın istenilen mesafeyi korumasını engellemektedir (5). Bu nedenle tümör yatağındaki kanser tam olarak eksize edilemez ve final patoloji raporunda cerrahi sınır pozitifliği meydana gelir. RHK nedeni ile yapılan NKC sonrası pozitif cerrahi sınırın (PCS) meydana gelmesi onkolojik açıdan istenen bir durum değildir ve bazı çalışmalarda lokal nüksü artırdığı gösterilmiştir (6). PCS'nin nadir görülmesi nedeni ile lokal nüks veya uzak metastazla olan ilişkisi ile seçilen cerrahi tekniğin (laparoskopi, robot yardımlı ve açık cerrahi) PCS'ye olan etkisi henüz net değildir.

$\mathrm{Bu}$ çalışmanın amacı, kapsamlı olarak RHK nedeni ile yapılan laparoskopik ve robot yardımlı parsiyel nefrektomi sonrası PCS insidansını araştırmak ve PCS'ye neden olabilecek sebepler ile PCS'nin kliniğge olan etkisini tartışmaktır.

\section{Yayın Toplama}

PUBMED ve GOOGLE SCHOLAR veri tabanları kullanılarak, 2000 ve 2015 yılları arasında "parsiyel nefrektomi", "nefron koruyucu cerrahi" ve "pozitif cerrahi sınır" kelimeleri, anahtar sözcük olarak araştırıldı. İngilizce olarak yazılmış ve konu ile ilişkili 50 adet makale gözden geçirildi ve bunların arasından takip süreleri 12 aydan daha uzun olan 16 makale çalışmaya dâhil edildi.

\section{Bulgular}

A-Nefron Koruyucu Cerrahi Sonrası Pozitif Cerrahi Sınır Insidansı

NKC sonrası PCS nadirdir ve literatüre bakıldığında insidansın $\% 0$ ile \%7 arasında değiştiği görülmektedir (7-10). Klasik bilgi olarak tümöre $1 \mathrm{~cm}$ mesafe bırakılarak sağlıklı parankimden yapılan eksizyon onkolojik prensipler için yeterlidir. Yeni çalışmalar ise daha fazla sağlıklı parankimin eksizyonuna gerek olmadığını tümöre en yakın sağlıklı alanın rezeksiyonunun onkolojik açıdan yeterli ve güvenilir sonuçlar verdiğini bildirmektedir $(11,12)$. Eğer vakalar elektif değilse ve büyük tümör hacimleri söz konusu ise PCS oranları artmaktadır (13-16).

\section{B-Cerrahi Tekniğin Pozitif Cerrahi Sınır Insidansına Etkisi}

Parsiyel nefrektomi açık, laparoskopik ve son yıllarda robot yardımlı olarak yapılmaktadır. Birçok çalışmada, APN'de PCS oranlarının düşük ve onkolojik açıdan güvenilir olduğu tespit edilmiştir $(6,16)$. Cerrahi tekniğe göre PCS insidans1; APN sonrası \%0-7, LPN sonrası \%1-8, RYPN sonrası ise \%4-6 olarak bulunmuştur (Tablo 1). Son yıllarda LPN'ye ve RYPN'ye olan ilgi artmakta, laparoskopik ve robot yardımlı cerrahide uzmanlaşmış doktorlar tarafından yapılan parsiyel nefrektomi vaka sayıları artmaktadır. Bunun nedeni LPN'nin ve RYPN'nin APN ile benzer morbiditeye sahip olması ve iyileşme döneminin daha kısa oluşudur. APN ile LPN ve RYPN'nin PCS açısından karşılaştırılmasında da benzer sonuçlara ulaşılmıştır (Tablo 2).

\section{C-Laparoskopik ve Robot Yardımlı Parsiyel Nefrektomi sonrası Pozitif Cerrahi Sınır Oranları}

Günümüzde LPN'nin koagulopatisi olan veya laparoskopik olarak cerrahisi mümkün olamayacak hastalar dışında kontrendikasyonu yoktur. LPN hiler, intraparankimal veya multiple senkron yerleşimli tümörlere ve soliter böbreklere uygulanabilmektedir. Laparoskopik tekniğin gelişmesi neticesinde LPN vaka sayıları artmış ve açık cerrahinin alternatifi olmuştur. Birçok çalışmada APN ile benzer PCS oranlarına sahiptir (17-22). 
Gill ve ark.'larının 771 LPN ve 1028 APN vakasını karşılaştırdıkları çalışmalarında, LPN sonrası operasyon ve eve dönüş sürelerinin $\mathrm{APN}^{\prime}$ ye oranla daha kısa olduğu bildirilmiştir. Bu çalışmada özellikle APN vakalarının daha kompleks ve elektif olmayan vakalar olduğu belir- tilmiştir. Ek olarak sıcak iskemi sürelerinin LPN'de daha uzun olduğu ve intraoperatif komplikasyonların LPN'de daha sık görüldüğü bildirilmiştir (3). Porpiglia'nın 2008 yılında APN ile LPN'yi karşılaştırdığ 1 bir meta-analizde; LPN'de sıcak iskemi sürelerinin açık cerrahiye göre daha

Tablo 1: Cerrahi tekniğe göre PCS insidansı

\begin{tabular}{|c|c|c|c|c|c|c|c|}
\hline Çalışma & Prosedür & Vaka Sayısı & Hasta Yaşı Ortalaması & Ortalama Tümör Boyutu $(\mathrm{cm})$ & PCS Sayısı & PCS Oranı (\%) & İzlem (ay) \\
\hline Gill et al (3) & Laparokopi & 744,00 & 60,00 & 2,80 & 6,00 & 1,00 & 36,00 \\
\hline Kwon et al (10) & Açıı & 777,00 & 66,00 & 2,60 & 51,00 & 15,00 & 24,00 \\
\hline Allaf et al (18) & Laparokopi & 48,00 & 60,00 & 2,40 & 1,00 & 7,00 & 36,00 \\
\hline Benway et al (45) & Laparokopi & 118,00 & 59,00 & 2,80 & 2,00 & 2,10 & 48,00 \\
\hline Benway et al (2) & Robot yardiml & 129,00 & 59,00 & 2,40 & 2,00 & 1,00 & 12,00 \\
\hline Bollens et al (33) & Laparokopi & 34,00 & 61,00 & 2,30 & 1,00 & 3,30 & 18,00 \\
\hline Desai et al (46) & Laparokopi & 50,00 & 65,00 & 2,20 & 5,00 & 2,50 & 56,00 \\
\hline Khalifeh et al (47) & Robot yardimli & 201,00 & 58,00 & 3,00 & 8,00 & 1,00 & 19,00 \\
\hline Lane et al (48) & Laparokopi & 74,00 & 64,00 & 2,90 & 2,00 & 3,00 & 70,00 \\
\hline Lifshitz et al (49) & Laparokopi & 184,00 & 58,00 & 3,00 & 6,00 & 18,00 & 18,00 \\
\hline Link et al (50) & Laparokopi & 144,00 & 56,00 & 2,60 & 5,00 & 3,20 & 18,00 \\
\hline Lopez-Costea et al (37) & Açıik & 137,00 & 61,00 & 3,10 & 9,00 & 3,50 & 70,00 \\
\hline Minervini et al (51) & Açık & 1152,00 & 60,00 & 3,40 & 26,00 & 6,50 & 54,00 \\
\hline Moinzadeh et al (21) & Laparokopi & 101,00 & 65,00 & 2,90 & 2,00 & 2,20 & 36,00 \\
\hline Permpongkosol et al (52) & Laparokopi & 85,00 & 58,00 & 2,40 & 2,00 & 3,40 & 48,00 \\
\hline Permpongkosol et al (52) & Açılk & 58,00 & 57,00 & 2,90 & 1,00 & 2,30 & 48,00 \\
\hline Peycelon et al (14) & Açılk & 61,00 & 64,00 & 5,60 & 11,00 & 1,70 & 70,00 \\
\hline Piper et al (29) & Açık & 67,00 & 61,00 & 3,00 & 7,00 & 18,00 & 29,00 \\
\hline Poppel et al (53) & Açılk & 268,00 & 62,00 & 3,00 & 3,00 & 10,00 & 111,00 \\
\hline Ray et al (44) & Aç,ik & 95,00 & 58,00 & 3,20 & 11,00 & 1,11 & 24,00 \\
\hline Raz et al (40) & Açılk & 114,00 & 67,00 & 2,90 & 7,00 & 11,50 & 71,00 \\
\hline Rogers et al (25) & Robot yardimli & 148,00 & 60,00 & 2,80 & 6,00 & 10,00 & 18,00 \\
\hline Scoll et al $(8)$ & Robot yardimli & 100,00 & 55,00 & 2,80 & 5,00 & 4,00 & 13,00 \\
\hline Timsit et al (5) & Açik & 61,00 & 60,00 & 3,20 & 0,00 & 5,00 & 73,00 \\
\hline Venkatesh et al (22) & Laparokopi & 123,00 & 59,00 & 2,60 & 3,00 & 0,00 & 16,00 \\
\hline Yossepowitch et al (6) & Aç, ik & 1334,00 & 62,00 & 3,50 & 77,00 & 2,50 & 39,00 \\
\hline Mottrie et al (25) & Robot yardımli & 62,00 & 60,00 & 2,80 & 2,00 & 2,00 & 18,00 \\
\hline Zigeuner et al (28) & Açılk & 111,00 & 61,00 & 2,50 & 6,00 & 5,50 & 77,00 \\
\hline Toplam & & 6580,00 & 60,57 & 2,91 & 9,54 & 5,23 & 41,79 \\
\hline
\end{tabular}

Tablo 2: Açık, laparoskopik ve robot yardımlı parsiyel nefrektominin pozitif cerrahi sınır oranlarının karşılaştırılması

\begin{tabular}{|c|c|c|c|c|c|c|c|}
\hline Çalışma & Prosedür & Vaka Sayısı & Hasta Yaşı Ortalaması & Ortalama Tümör Boyutu (cm) & PCS Sayısı & PCS Oranı (\%) & Izlem (ay) \\
\hline Gill et al (3) & Laparokopi & 744,00 & 60,00 & 2,80 & 6,00 & 1,00 & 36,00 \\
\hline Allaf et al (18) & Laparokopi & 48,00 & 60,00 & 2,40 & 1,00 & 7,00 & 36,00 \\
\hline Benway et al (45) & Laparokopi & 118,00 & 59,00 & 2,80 & 2,00 & 2,10 & 48,00 \\
\hline Bollens et al (33) & Laparokopi & 34,00 & 61,00 & 2,30 & 1,00 & 3,30 & 18,00 \\
\hline Desai et al (46) & Laparokopi & 50,00 & 65,00 & 2,20 & 5,00 & 2,50 & 56,00 \\
\hline Lane et al (48) & Laparokopi & 74,00 & 64,00 & 2,90 & 2,00 & 3,00 & 70,00 \\
\hline Lifshitz et al (49) & Laparokopi & 184,00 & 58,00 & 3,00 & 6,00 & 18,00 & 18,00 \\
\hline Link et al (50) & Laparokopi & 144,00 & 56,00 & 2,60 & 5,00 & 3,20 & 18,00 \\
\hline Moinzadeh et al (21) & Laparokopi & 101,00 & 65,00 & 2,90 & 2,00 & 2,20 & 36,00 \\
\hline Permpongkosol et al (52) & Laparokopi & 85,00 & 58,00 & 2,40 & 2,00 & 3,40 & 48,00 \\
\hline Venkatesh et al (22) & Laparokopi & 123,00 & 59,00 & 2,60 & 3,00 & 0,00 & 16,00 \\
\hline Benway et al (2) & Robot yardiml & 129,00 & 59,00 & 2,40 & 2,00 & 1,00 & 12,00 \\
\hline Khalifeh et al (47) & Robot yardimi & 201,00 & 58,00 & 3,00 & 8,00 & 1,00 & 19,00 \\
\hline Rogers et al (25) & Robot yardiml & 148,00 & 60,00 & 2,80 & 6,00 & 10,00 & 18,00 \\
\hline Scoll et al ( 8 ) & Robot yardimli & 100,00 & 55,00 & 2,80 & 5,00 & 4,00 & 13,00 \\
\hline Mottrie et al (25) & Robot yardimh & 62,00 & 60,00 & 2,80 & 2,00 & 2,00 & 18,00 \\
\hline Toplam & & 2345,00 & 59,81 & 2,67 & 3,63 & 3,98 & 30,00 \\
\hline
\end{tabular}


Tablo 3: Laparoskopik Parsiyel Nefrektomi sonrası Pozitif Cerrahi Sınır Oranları

\begin{tabular}{|c|c|c|c|c|c|c|c|}
\hline Çalışma & Prosedür & Vaka Sayısı & Hasta Yaşı Ortalaması & Ortalama Tümör Boyutu $(\mathrm{cm})$ & PCS Sayısı & PCS Oranı (\%) & İlem (ay) \\
\hline Gill et al (3) & Laparokopi & 744,00 & 60,00 & 2,80 & 6,00 & 1,00 & 36,00 \\
\hline Allaf et al (18) & Laparokopi & 48,00 & 60,00 & 2,40 & 1,00 & 7,00 & 36,00 \\
\hline Benway et al (45) & Laparokopi & 118,00 & 59,00 & 2,80 & 2,00 & 2,10 & 48,00 \\
\hline Bollens et al (33) & Laparokopi & 34,00 & 61,00 & 2,30 & 1,00 & 3,30 & 18,00 \\
\hline Desai et al (46) & Laparokopi & 50,00 & 65,00 & 2,20 & 5,00 & 2,50 & 56,00 \\
\hline Lane et al (48) & Laparokopi & 74,00 & 64,00 & 2,90 & 2,00 & 3,00 & 70,00 \\
\hline Lifshitz et al (49) & Laparokopi & 184,00 & 58,00 & 3,00 & 6,00 & 18,00 & 18,00 \\
\hline Link et al (50) & Laparokopi & 144,00 & 56,00 & 2,60 & 5,00 & 3,20 & 18,00 \\
\hline Moinzadeh et al (21) & Laparokopi & 101,00 & 65,00 & 2,90 & 2,00 & 2,20 & 36,00 \\
\hline Permpongkosol et al (52) & Laparokopi & 85,00 & 58,00 & 2,40 & 2,00 & 3,40 & 48,00 \\
\hline Venkatesh et al (22) & Laparokopi & 123,00 & 59,00 & 2,60 & 3,00 & 0,00 & 16,00 \\
\hline Total & & 1705,00 & 60,45 & 2,63 & 3,18 & 4,15 & 36,36 \\
\hline
\end{tabular}

Tablo 4: Robot Yardımlı Parsiyel Nefrektomi sonrası Pozitif Cerrahi Sınır Oranları

\begin{tabular}{|c|c|c|c|c|c|c|c|}
\hline Çalışma & Prosedür & Vaka Sayısı & Hasta Yaşı Ortalaması & Ortalama Tümör Boyutu (cm) & PCS Sayısı & PCS Orani $(\%)$ & İlem (ay) \\
\hline Benway et al (2) & Robot yardimil & 129,00 & 59,00 & 2,40 & 2,00 & 1,00 & 12,00 \\
\hline Khalifeh et al (47) & Robot yardimi & 201,00 & 58,00 & 3,00 & 8,00 & 1,00 & 19,00 \\
\hline Rogers et al (25) & Robot yardimli & 148,00 & 60,00 & 2,80 & 6,00 & 10,00 & 18,00 \\
\hline Scoll et al $(8)$ & Robot yardimli & 100,00 & 55,00 & 2,80 & 5,00 & 4,00 & 13,00 \\
\hline Mottrie et al (25) & Robot yardiml & 62,00 & 60,00 & 2,80 & 2,00 & 2,00 & 18,00 \\
\hline Toplam & & 640,00 & 58,40 & 2,76 & 4,60 & 3,60 & 16,00 \\
\hline
\end{tabular}

fazla ve laparoskopinin öğrenme eğrisinin uzun oluşunun LPN'nin dezavantajları olduğu ifade edilmiştir. Fakat PCS açısından APN ile benzer sonuçlara sahip olduğu belirtilmiştir (19). Moinzadeh ve ark.'larının yaptığı bir çalışmada da; 100 LPN vakasında PCS oranı \%2 bulunmuş, 3 yıl boyunca onkolojik açıdan takip edilmiş ve sonuçta hastalıksız sağ kalım oranı \%86 olarak belirtilmiştir (21). Breda ve ark.'larının yaptığı 855 vakayı içeren çalışmada, LPN uygulanan $4 \mathrm{~cm}$ altındaki tümörlerde PCS oranı $\% 2,4$ olarak bulmuştur. Fakat bu çalışmada intraparankimal tümör oranı vakaların sadece \%10'unu oluşturmaktadır (23). Birçok çalışmada LPN sonrası PCS açısından benzer oranlar bulunmaktadır (Tablo 3).

Son 10 yıldır RHK vakalarında RYPN, LPN'ye alternatif olarak üroloji dağarcığına girmiştir. Özellikle cerrahi alanın daha net ve büyütülerek görülmesi, robot kollarının eklemli olması, cerrahın ergonomik açıdan daha konforlu olması ve sıcak iskemi sürelerinin kısa oluşu laparoskopiye göre avantajlarıdır. Mottrie ve Rogers'in yaptığı iki farklı çalışmada PCS oranları \%2 olarak saptanmış ve cerrah tecrübelerinin artması ile bu oranların düştügü vurgulanmıştır $(24,25)$. Scoll ve ark.'larının yaptığı 100 RYPN vakasını içeren bir çalışmada, tümörlerin \%50'sinin intraparankimal ve \%17'sinin ise renal hiluma $7 \mathrm{~mm}$ 'den daha yakın olduğu belirtilmiş, vakaların elektif olmamasına rağmen PCS oranın \%5,7 olduğu bildirilmiştir (8). Khalief ve ark.'larının yaptığ $\mathrm{LPN}$ ve RYPN vakalarının intraoperatif ve postoperatif komplikasyonlar, sıcak iskemi süreleri ve PCS oranları açısından karşılaştırıldığı başka bir çalışmada da; RYPN grubunda hastaların daha obez ve tümörlerin daha kompleks olmasına rağmen, 4 parametrede de LPN'ye göre daha iyi sonuçlar elde edildiği vurgulanmış, PCS oranları LPN için \%5,6 RYPN için ise \%2,9 olduğu bildirilmiştir.

Sonuç olarak literatür incelendiğinde LPN ve RYPN sonrası PCS oranları; LPN'de \%4,15, RYPN'de ise \%3,6 olarak saptanmış, RHK nedeni ile yapılan parsiyel nefrektomi sonrası PCS oranları açısından anlamlı bir fark bulunmamıştır. Fakat hastalar R.E.N.A.L. (tümör çapı, tümörün endofitik veya ekzofitik oluşu, tümörün toplayıcı sisteme olan mesafesi, tümörün polar bölgelerle ilişkisi) nefrometri skorları ile karşılaştırılacak olursa RYPN'de seçilen vakalar daha komplekstir ve buna rağmen PCS oranları LPN'ye oranla daha düşük görünmektedir (Tablo 4).

\section{D-Elektif Olmayan Nefron Koruyucu Cerrahilerin Pozitif Cerrahi Sınır Insidansına Etkisi}

Özellikle soliter böbreklere uygulanan NKC sonrası glomerüler filtrasyon hızının minimal etkilenmesi için sağlıklı parankimin korunmasına önem verilmelidir. Gill ve ark'larının 430 vakadan oluşan LPN yapılmış soliter böbreklerde PCS oranın \%8'lere ulaştı̆̆ı saptanmıştır (26). Saranchuk ve ark.'larının yaptığı APN vakalarını içeren bir çalışmada ise; $4 \mathrm{~cm}$ 'den büyük tümörlere uygulanan NKC sonrası PCS oranlarının \%15 olduğu bulunmuştur (13).

Tümör lokalizasyonu ve PCS‘yi araştıran çok fazla çalışma yoktur. Bensallah ve ark.'larının yaptığ 1 bir retrospektif çalışmada, santral yerleşimli tümörler ile egzofitik tümörler karşılaştırılmış ve santral yerleşimli tümörlerde PCS oranı \%26 olarak bulunmuştur (27). Elektif olmayan NKC'lerde PCS oranı daha fazla saptanmış fakat yine aynı çalışmalarda PCS'nin soliter böbreklerde de hasta sağ kalımına etkisinin olmadığı belirtilmiştir. 


\section{D-Renal Hücreli Kanserde Histolojik Alt Tiplerin Pozitif Cerrahi Sınır İnsidansına Etkisi}

RHK'in histolojik alt tipleri ile PCS oranlarını karşılaştıran laparoskopik ve robot yardımlı nefron koruyucu cerrahi çalışması bulunmamaktadır. Elimizdeki bilgiler Kwon ve ark.'larının yaptığı 777 vakalık APN serisinden sağlanmıştır. Bu çalışmada, Heidelberg sinıflamasına göre düşük malignite potansiyeli olan (onkositom, anjiomiyolipom, papiller RHK Tip 1, kromofob RHK ve diğer benign böbrek tümörleri) ve yüksek malignite potansiyeli olan tümörler (berrak hücreli RHK, toplayıcı sistem karsinomu, papiller RHK Tip 2 ve sarkomatöz değişiklikler ihtiva eden tümörler) PCS açısından karşılaştırılmış ve anlamlı bir fark saptanmamıştır (10). Bu makalede ek olarak yüksek malignite potansiyeli bulunan tümörlerde lokal rekürrensin daha yüksek oranlarda görülebileceğine vurgu yapılmıştır.

E-Frozen Biyopsinin Nefron Koruyucu Cerrahideki Yeri

NKC sonrası cerrahi bölgenin rutin olarak intraoperatif değerlendirilmesi gerekmektedir. Değerlendirme önce inspeksiyonla olmalı tümör yatağında rest tümör varlığına bakılmalı, gerek görülürse ek rezeksiyon yapılmalıdır. Bazı kliniklerde intraoperatif patolog konsültasyonu istenerek eksize edilen tümör makroskobik açıdan incelenmektedir, patoloğun uygun gördüğ̈̈ yerlerden frozen biyopsiler alınıp değerlendirme yapılmaktadır. Genel görüş rutin frozen biyopsinin gerek olmadığı yönündedir. Çünkü frozen biyopsi neticesinde yanlış pozitif ve negatiflikler olabilmekte ve final patoloji raporuyla çelişen sonuçlar ortaya çıkabilmektedir (28-32). Frozen biyopsi daha çok cerrahın şüpheye düştüğü, eksizyon sınırlarının muğlak olduğu durumlarda önerilmektedir.

\section{F-Pozitif Cerrahi Sınır Nasıl Önlenir}

LPN ve RYPN'de PCS nedenleri; intaroperatif cerrahi alanın net görüntülenememesi, cerrahi oryantasyonun sağlanamaması ve renal parankimin daha derinlerine inen infiltran tümörlerdir. Tümör bölgesinin rezeksiyon esnasında net değerlendirilememe sebebi en sik renal arter ve venin klemplenmemesi nedeniyledir. Özellikle küçük tümörlerde eksizyon esnasında tümör yatağına hemoraji, görüntünün netliğinin bozulmasına neden olarak PCS oluşumunu artırabilir $(33,34)$. Bu negatif faktörü önlemek için intraoperatif ultrasonografi (USG) kullanılmaktadır. İntraoperatif USG ile tümör sınırları net değerlendirilmekte ve tümör derinliği boyunca daha güvenli rezeksiyon yapılabilmektedir (35). Son dönemde yapilan çalışmalarda gerçek zamanlı üç boyutlu tümör görüntüsü oluşturularak operasyon sonrası PCS oluşumu engellenmeye çalışılmaktadır (36).

\section{G-Pozitif Cerrahi Sınırın Sağ Kalıma Etkisi}

NKC sonrası PCS'ın sağ kalıma etkisi bilinmemektedir. Bu konuda kapsamlı randomize çalışmalar yoktur. Yossepowitch ve ark.'larının ortalama 40 aylık takip süresi olan ve 1257 APN vakasını içeren retrospektif çalışmalarında, lokal ve uzak rekürrensi artıran tek parametrenin tümör boyutu olduğu bildirilmiştir (6). Lopez-Costea ve ark.'larının yaptığı ve 128 APN vakasını içeren diğer bir çalışmada da; PCS olan vakalar ortalama 70 ay takip edilmiş ve negatif cerrahi sınırı olan hastalarla lokal ve uzak rekürrens oranlarının benzer olduğu belirtilmiştir (37). Fakat daha kısa takip sürelerinin olduğu çalışmalarda, PCS'ın lokal rekürrensi arttırdığı ama uzak metastaz ve sağ kalım üzerine bir etkisi olmadığı saptanmıştır
$(14,27,38)$. Ek olarak Bensallah ve ark.'larının yaptığı çalışmada lokal rekürrensin PCS olan hastalarda, negatif cerrahi sınırı olanlara kıyasla daha kısa zamanda geliştiği belirtilmiştir (PCS vakalarında lokal nüksün gelişme süresi 27 ay, cerrahi sınır negatif olan vakalarda 45 ay) (27). Bernhard ve ark.'larının yaptığ 809 vakalık çalışmada da PCS oranı $\% 2$ olarak bulunmuş ve bu hastaların 3'te 1'inde 23 aylık izlem sonunda lokal nüks geliştiği belirtilmiştir (39). Özellikle malignite potansiyeli yüksek olan vakalarda saptanan PCS sonrası lokal nüksün gelişme ihtimali daha fazladır (10). Sonuç olarak PCS öncelikle yüksek malingite potansiyeli olan hastalarda lokal rekürrensi artırmakta fakat sağ kalım üzerine direkt etki yapmamaktadır. Bu nedenle PCS sonrası ikincil cerrahi girişimler ertelenmeli fakat hastalarda lokal rekürrens ihtimali göz önüne alınarak aktif olarak daha sıkı takip edilmelidir.

\section{H-Pozitif Cerrahi Sınırın Tedavisi}

PCS'nin olması, onkolojik prensipler nedeniyle istenilmeyen bir durumdur. Tedavi için iki seçenek bulunmaktadır, hasta aktif olarak takip edilmeli veya tümör yatağına ilave tedavi uygulanmalıdır (radikal nefrektomi, yeniden parsiyel nefrektomi, minimal invaziv ablasyon tedavileri). Fakat yap1lan çalışmalarda PCS'nin sağ kalıma etkisi saptanmadığı için genelde takip protokolü öne çıkmaktadır. Pozitif cerrahi sınır mevcut olan hastalarda takip yolunun seçilmesinde bir başka etken de, yapılan bazı çalışmalarda PCS olan hastalara uygulanan radikal nefrektomi sonrasi patoloji raporlarında, hastaların yalnız \%7-15'inde tümörlü dokunun saptanmış olmasıdir $(40,41)$. Bunlara ilave olarak, pozitif cerrahi sinır nedeni ile radikal nefrektomi uygulanan hastalarda kronik böbrek yetersizliği gelişme ihtimali artmakta, sonuç olarak sağ kalım negatif yönde etkilenmektedir $(42,43)$. Parsiyel nefrektominin yeniden yapılması ise cerrahi açıdan zorluklar taşımaktadır ve morbiditesi yüksektir. Dahası; PCS sonrası yeniden yapılan parsiyel nefrektomilerde de rezeke edilen yeni dokularda tümör çıma oranı sadece \%5-8 olarak bulunmuştur $(14,44)$. Fakat çalışmaların yorum bölümünde yeniden parsiyel nefrektominin özellikle Fuhrman derecesi yüksek olan ve sarkomatöz komponent barındıran hastalara uygulanabileceği belirtilmiştir. Radyofrekans ablasyonu ve kriyoablasyon gibi minimal invaziv girişimlerde de patoloji için gerekli dokunun sağlanamadığ ve hastanın görüntüleme yöntemleriyle (MR, BT) takibinde artefakt oluşturdukları gerekçesiyle tercih edilmemektedir. Sonuçta, parsiyel nefrektomi sonrası olan PCS için uygun tedavinin aktif takip olduğu söylenebilir.

\section{Sonuç}

Sonuç olarak literatür incelendiğinde, laparoskopik ve robot yardımlı parsiyel nefrektomi sonrası pozitif cerrahi sınır (PCS) ortalamaları \%3-6 oranında, açık parsiyel nefrektomi ile benzer sonuçlara sahip olduğu görülmektedir. RYPN'nin R.E.N.A.L. nefrometri skoru yüksek vakalarda LPN'ye oranla pozitif cerrahi sınır gelişmesini önlemede daha etkili olduğu görülmektedir fakat bunun için randomize çalışmalara ihtiyaç vardır.

\section{Kaynaklar}

1. Fergany AF, Hafez KS, Novick AC. Long-term results of nephron sparing surgery for localized renal cell carcinoma: 10-year follow-up. J Urol 2000; 163:442-5. 
2. Benway BM, Bhayani SB, Rogers CG, et al. Robot-assisted partial nephrectomy: an international experience. Eur Urol 2010; 57: 815-20.

3. Gill IS, Kamoi K, Aron M, Desai MM. 800 Laparoscopic partial nephrectomies: a single surgeon series. J Urol 2010; 183: 34-42.

4. Vermooten V: Indications for conservative surgery incertain renal tumors: a study based on the growth pattern of the cell carcinoma. J Urol 64: 200-208, 1950

5. Timsit MO, Bazin JP, Thiounn N, Fontaine E, Chrétien Y, Dufour B, Méjean A. Prospective study of safety margins in partial nephrectomy: intraoperative assessment and contribution of frozen section analysis. Urology. 2006 May; 67(5):923-6

6. Yossepowitch O, Thompson RH, Leibovich BC, et al Positive surgical margins at partial nephrectomy: predictors and oncological outcomes. J Urol 2008; 179:2158-63.

7. Gill IS, Kavoussi LR, Lane BR, et al. Comparison of 1,800 laparoscopic and open partial nephrectomies for single renal tumors. J Urol 2007; 178:41-6.

8. Scoll BJ, Uzzo RG, Chen DY, et al. Robot-assisted partial nephrectomy: a large single-institutional experience. Urology 2010; 75:1328-34.

9. Marszalek M, Carini M, Chlosta P, et al. Positive surgical margins after nephronsparing surgery. Eur Urol 2012; 61:757-63.

10. Kwon EO, Carver BS, Snyder ME, et al. Impact of positive surgical margins in patients undergoing partial nephrectomy for renal cortical tumors. BJU Int. 2007; 99:286-9.

11. Sutherland SE, Resnick MI, MacLennan GT, Goldman HB. Does the size of the surgical margin in partial nephrectomy for renal cell cancer really matter? J Urol 2002; 167:61-4.

12. Castilla EA, Liou LS, Abrahams NA, et al. Prognostic importance of resection margin width after nephronsparing surgery for renal cell carcinoma. Urology 2002; 60:993-7.

13. Saranchuk JW, Touijer AK, Hakimian P, Snyder ME, Russo P. Partial nephrectomy for patients with a solitary kidney: the Memorial Sloan-Kettering experience. BJU Int. 2004; 94:1323-8.

14. Peycelon M, Hupertan V, Comperat E, et al. Long-term outcomes after nephron sparing surgery for renal cell carcinoma larger than $4 \mathrm{~cm}$. J Urol 2009; 181:35-41.

15. Lee DJ, Hruby G, Benson MC, McKiernan JM. Renal function and oncologic outcomes in nephron sparing surgery for renal masses in solitary kidneys. World J Urol 2011; 29:343-8.

16. Wszolek MF, Kenney PA, Lee Y, Libertino JA. Comparison of hilar clamping and non-hilar clamping partial nephrectomy for tumors involving a solitary kidney. BJU Int 2010; 107:1886-92.

17. Gill IS, Matin SF, Desai MM, et al. Comparative analysis of laparoscopic versus open partial nephrectomy for renal tumours in 200 patients. J Urol 2003; 170:64-8.

18. Allaf ME, Bhayani SB, Rogers C, Varkarakis I, Link RE, Inagaki $\mathrm{T}$ et al: Laparoscopic partial nephrectomy: evaluation of long-term oncological outcome. J Urol 2004; 172: 871.

19. Porpiglia F, Fiori C, Terrone C, Bollito E, Fontana D and
Scarpa RM: Assessment of surgical margins in renal cell carcinoma after nephron sparing: a comparative study: laparoscopy vs open surgery. J Urol 2005; 173: 1098.

20. Link RE, Bhayani SB, Allaf ME, Varkarakis I, Inagaki T, Rogers $C$ et al: Exploring the learning curve, pathological outcomes and perioperative morbidity of laparoscopic partial nephrectomy performed for renal mass. J Urol 2005; 173: 1690.

21. Moinzadeh A, Gill IS, Finelli A, Kaouk J and Desai M: Laparoscopic partial nephrectomy: 3-year followup. J Urol 2006; 175: 459.

22. Venkatesh R, Weld K, Ames CD, Figenshau SR, Sundaram $\mathrm{CP}$, Andriole GL et al: Laparoscopic partial nephrectomy for renal masses: effect of tumor location. Urology 2006; 67: 1169.

23. Breda A., Stepanian SV, Liao J, et al. Positive margins in laparoscopic partial nephrectomy in 855 cases: a multiinstitutional survey from the United States and Europe. J Urol 2007; 178: 47-50

24. Mottrie A, De Naeyer G, Schatteman P, et al. Impact of the learning curve on perioperative outcomes in patients who underwent robotic partial nephrectomy for parenchymal renal tumors. Eur Urol 2010; 58: 127-33.

25. Rogers CG, Menon M, Weise ES, et al. Robotic partial nephrectomy: a multi institutional analysis. J Robotic Surg 2008; 2: 141-3.

26. Gill IS, Columbo JR Jr, Moinzadeh A et al: Laparoscopic partial nephrectomy in solitary kidney. J Urol 2006; 175: 454

27. Bensalah K, Pantuck AJ, Rioux-Leclercq N, et al. Positive surgical margin appears to have negligible impact on survival of renal cell carcinomas treated by nephronsparing surgery. Eur Urol 2010; 57:466-73.

28. Zigeuner R, Quehenberger F, PummerK, Petritsch $\mathrm{P}$, HubmerG. Long term results of nephron-sparing surgery for renal cell carcinoma in 114 patients: risk factors for progressive disease. BJU Int 2003; 92: 567-71.

29. Piper NY, Bishoff JT, Magee C, et al. Is a 1-cm margin necessary during nephron-sparing surgery for renal cell carcinoma? Urology 2001; 586:849-52.

30. Carini M, Minervini A, Lapini A, Masieri L, Serni S. Simple enucleation for the treatment of renal cell carcinoma between 4 and $7 \mathrm{~cm}$ in greatest dimension: progression and long-term survival. J Urol 2006; 175:2022-6.

31. Duvdevani M, Laufer M, Kastin A, et al. Is frozen section analysis in nephron sparing surgery necessary? A clinic pathological study of 301 cases. J Urol 2005; 173:385-7.

32. Kubinski DJ, Clark PE, Assimos DG, Hall MC. Utility of frozen section analysis of resection margins during partial nephrectomy. Urology 2004; 64:31-4.

33. Bollens R, Rosenblatt A, Espinoza BP, et al. Laparoscopic partial nephrectomy with "on-demand" clamping reduces warm ischemia time. Eur Urol 2007; 52:804-10.

34. Duvdevani M, Mor Y, Kastin A, et al. Renal artery occlusion during nephron-sparing surgery: retrospective review of 301 cases. Urology 2006; 68:960-3.

35. Nguyen TT, Parkinson JP, Kuehn DM, Winfield HN. Technique for ensuring negative surgical margins during laparoscopic partial nephrectomy. J Endourol 2005; 19:410-5.

36. Teber D, Guven S, Simpfendorfer T et al. Augmented reality: a new tool to improve surgical accuracy during 
laparoscopic partial nephrectomy? Preliminary in vitro and in vivo results. Eur Urol 2009; 56:332-8.

37. Lopez-Costea MA, Fumadó L, Lorente D et al. Positive margins after nephron sparing surgery for renal cell carcinoma: long-term follow-up of patients on active surveillance. BJU Int 2010; 106:645-8.

38. Marszalek M, Meixl H, Polajnar M, et al. Laparoscopic and open partial nephrectomy: a matched-pair comparison of 200 patients. Eur Urol 2009; 55: 1606-15.

39. Bernhard JC, Pantuck AJ, Wallerand H, et al. Predictive factors for ipsilateral recurrence after nephron-sparing surgery in renal cell carcinoma. Eur Urol 2010; 57: 1080-6.

40. Raz O,Mendlovic S, Shilo Y, et al. Positive surgical margins with renal cell carcinoma have a limited influence on long-term oncological outcomes of nephron sparing surgery. Urology 2010; 75:277-80

41. Sundaram V, Figenshau RS, Roytman TM, et al. Positive margin during partial nephrectomy: does cancer remain in the renal remnant? Urology 2011; 77: 1400-3.

42. Go AS, Chertow GM, Fan D, McCulloch CE, Hsu C. Chronic kidney disease and the risks of death, cardiovascular events, and hospitalization. N Engl J Med 2004; 351:1296-305.

43. Weight CG, Larson BT, Fergany AF, et al. Nephrectomy induced chronic renal insufficiency is associated with increased risk of cardiovascular death and death from any cause in patients with localized cT1b renal masses. J Urol 2010; 183:1317-23.

44. Ray ER, Turney BW, Singh R, Chandra A, Cranston DW, O'Brien TS. Open partial nephrectomy: outcomes from two UK centers. BJU Int 2006; 97: 1211-5.

45. Benway BM, Bhayani SB, Rogers CG, et al. Robot assisted partial nephrectomy versus laparoscopic partial nephrectomy for renal tumors: a multi-institutional analysis of perioperative outcomes. J Urol 2009; 182:86673.

46. Desai PJ, Andrews PE, Ferrigni RG, Castle EP. Laparoscopic partial nephrectomy at the Mayo Clinic Arizona: follow-up surveillance of positive margin disease. Urology 2008; 71: 283-6.
47. Khalifeh A, Autorino R, Hillyer SP, Laydner H, Eyraud $\mathrm{R}$, Panumatrassamee $\mathrm{K}$, et al. Comparative outcomes and assessment of trifecta in 500 robotic and laparoscopic partial nephrectomy cases: a single surgeon experience. J Urol. 2013 Apr; 189(4):1236-42.

48. Lane BR, Gill IS. 7-year oncological outcomes after laparoscopic and open partial nephrectomy. J Urol. 2010 Feb; 183(2):473-9.

49. Lifshitz DA, Shikanov SA, Deklaj T, Katz MH, Zorn KC, Eggener SE, et al. Laparoscopic partial nephrectomy: a single-center evolving experience. Urology. 2010 Feb; 75(2):282-7.

50. Link RE, Bhayani SB, Allaf ME, Varkarakis I, Inagaki T, Rogers C, et al. Exploring the learning curve, pathological outcomes and perioperative morbidity of laparoscopic partial nephrectomy performed for renal mass. J Urol. 2005 May; 173:1690-4.

51. Minervini A, Ficarra V, Rocco F, et al. Simple enucleation is equivalent to traditional partial nephrectomy for renal cell carcinoma: results of a nonrandomized, retrospective, comparative study. J Urol 2011; 185:1604-10.

52. Permpongkosol S, Bagga HS, Romero FR, Sroka M, Jarrett TW, et al. Laparoscopic versus open partial nephrectomy for the treatment of pathological T1N0M0 renal cell carcinoma: a 5-year survival rate. J Urol. 2006 Nov; 176(5):1984-8

53. Van Poppel H, Da Pozzo L, Albrecht W, Matveev V, Bono A, Borkowski A, et al. A prospective, randomised EORTC intergroup phase 3 study comparing the oncologic outcome of elective nephron-sparing surgery and radical nephrectomy for low-stage renal cell carcinoma. Eur Urol. 2011 Apr; 59(4):543-52.

Yazışma Adresi:

Hasan Anul Atalay,

Okmeydanı Ĕ̆itim ve Araştırma Hastanesi, Üroloji Kliniği,

Şişli, İstanbul

Tel: +90 5333234133

e-mail: anilatalay@gmail.com 